\title{
The identification of key factors determining the sustainability of stormwater systems
}

\author{
Sabina Kordana ${ }^{1, *}$ \\ ${ }^{1}$ Rzeszow University of Technology, Department of Infrastructure and Water Management, \\ al. Powstańców Warszawy 6, 35-959 Rzeszów, Poland
}

\begin{abstract}
Land cover changes may cause a disturbance in the water cycle, the consequence of which is an increase in the volume of stormwater runoff. In such a situation, the use of traditional stormwater systems leads to a number of problems, including the hydraulic overload of these systems and the deterioration of rivers. Therefore, stormwater management clearly affects the quality of life in a particular area. In order to facilitate effective stormwater management, the paper identifies and assesses factors that impact the sustainability of stormwater systems. Using the premises of PESTLE analysis, these factors were categorized as Political, Economic, Social, Technological, Legal, or Environmental. Assessments from an expert team were also used to identify elements that are crucial for the development of innovative solutions for stormwater management.
\end{abstract}

\section{Introduction}

Water management, which includes the design and planning as well as the operation and management of individual components [1] is one of major determinants of the quality of life in a particular area [2]. Among others, it encompasses the disposal of rainwater which is a valuable source of water for non-potable purposes on the one hand [3, 4], and a source of numerous problems on the other $[5,6]$. The problems may be related to roof rainwater quality [7], the stormwater system and the area where it is located [8,9] or the receiving water body [10]. Social costs resulting from these problems are, in turn, particularly evident in strongly urban areas [11]. Therefore, measures need to be taken to improve the efficacy of the management of stormwater generated within urban catchment basins and the safety [12] of the systems.

Although the recent trend for reducing the negative environmental impact of technologies [13-15] could also be observed in stormwater management [16-18], the possibilities for further developments are limited in this area. This is due to the lack of detailed analyses identifying and assessing criteria that determine the approach to stormwater management. In response to this issue, the article identifies factors of key importance for the sustainability of stormwater management systems. Individual factors are also evaluated for their importance for proper stormwater management. The PESTLE analysis, i.e. a foresight evaluation tool, was chosen as the study method.

\footnotetext{
${ }^{*}$ Corresponding author: sk@prz.edu.pl
} 


\section{Methods}

PESTLE facilitates identification and classification of external factors impacting the study subject into Political, Economic, Social, Technological, Legal, and Environmental issues [19]. The tool is usually used for evaluation of organizations and factors that impact their functioning [19]; however, it may also prove useful in verification of processes or technologies, i.e. in the broadly defined environmental engineering $[20,21]$.

The procedure of the PESTLE analysis, carried out as part of the study presented in this article, is outlined in Figure 1. The first stage consisted in the identification of factors that impact the sustainability of stormwater management systems and in the classification of these factors into six categories. The stage was based on a brainstorming approach following the analysis and synthesis of knowledge within a team of experts. Next, on the basis of guidelines identified in the reference [22], three factors of highest importance for the sustainability of stormwater systems were identified in each group. Surveys were developed to assess the impact and uncertainty of each of these expert-identified factors. The surveys were based on the 7-point Likert scale. The Impact/Uncertainty grid [23] was constructed on the basis of survey outcomes. The analysis of the grid facilitated identification of factors that are of the highest importance for the sustainability of stormwater systems as well as the key areas of uncertainty.

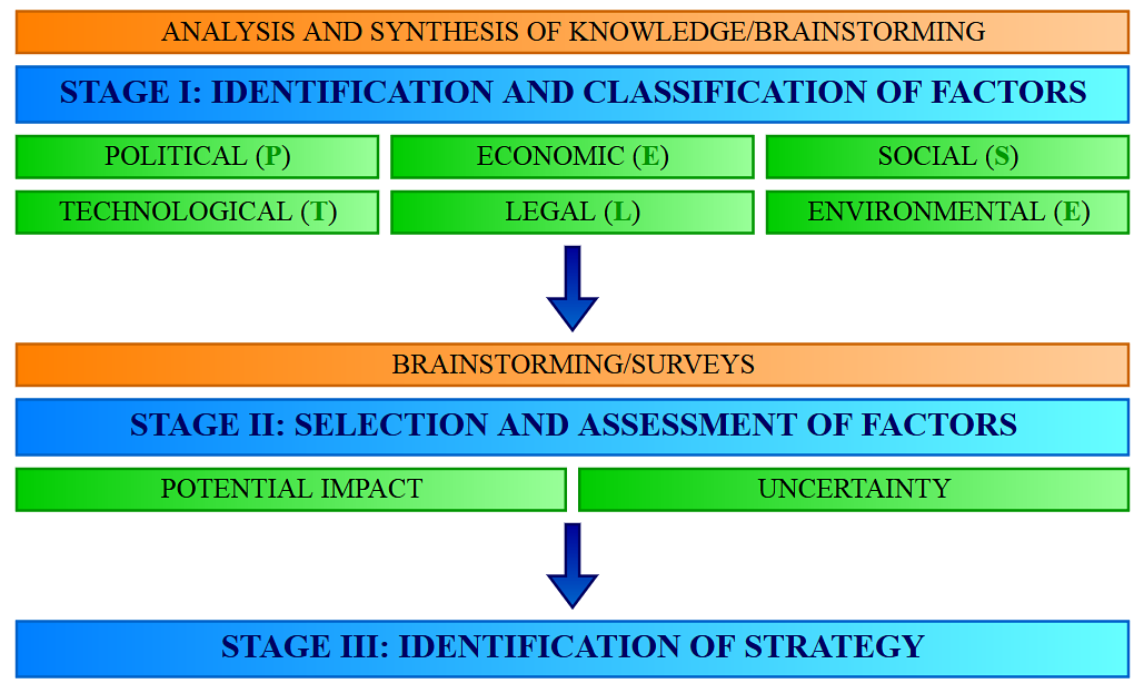

Fig. 1. Research plan.

\section{Stormwater Best Management Practices}

Stormwater Best Management Practices (BMPs) are based on the concept of managing stormwater within the catchment basins in which it is generated or on the flattening of the hydrograph of its outflow into the receiving body of water. In the former case, facilities for surface or underground infiltration of stormwater into the soil or rainwater harvesting systems may be used [24-26]. If the above solutions are not recommended, retention facilities may be used [27-29], including basins comprising an element of stormwater treatment plants [30].

The use of these facilities is proecological as it brings about numerous benefits to the environment, the operators of stormwater systems, and the residents of catchment areas alike. 


\section{Identification and classification of factors}

The first stage of the analysis consisted in the identification of factors that determine the possible sustainability of stormwater systems. As determined by a team of 15 experts representing stormwater system research, construction, and operation specialists, as well as residents of the areas being drained, all factors were classified into the following categories.

\section{Political factors (P):}

1. Innovative stormwater BPMs support strategies

2. Strategies for implementation of EU regulations on stormwater management

3. Sustainability implementation strategy

4. Promotion of the implementation of stormwater BMPs at the local government level

5. The scale of public support for catchment basins of different characteristics

6. The awareness of state authorities with regard to the importance of stormwater BMPs

7. The level of administrative obstacles in the implementation of stormwater BMPs

\section{Economic factors (E):}

1. The cost of construction of innovative stormwater BMPs

2. The scale of public support and the availability of other funds for the construction of stormwater BMPs

3. Operating costs of stormwater BMPs

4. Rainwater discharge costs

5. The level of rainwater harvesting

6. Management of stormwater infrastructure

\section{Social factors (S):}

1. Level of social acceptance of stormwater BMPs

2. Residents' lifestyles

3. Social tendencies towards the implementation of innovative solutions in water management

4. Willingness to cooperate between different groups of stakeholders in the decision-making process related to the choice of a stormwater discharge system

5. Availability of trained stormwater management system designers

6. Scale of social costs of inappropriate stormwater management

7. Residents' safety levels

8. The effectiveness of landscape architecture development within the stormwater system

9. The efficacy of microclimate improvement due to stormwater BMPs

\section{Technological factors $(T)$ :}

1. Automation of the stormwater BMPs construction processes

2. The supply of innovative systems for stormwater management

3. Availability of areas for the construction of stormwater BMPs

4. Availability of tools to facilitate the design of stormwater BMPs

5. Availability of stormwater BMPs adequate to match the size, landform, and characteristics of the area to be drained

6. Efficacy of the transfer of innovative solutions from research to the industry

7. Efficacy of the assessment of innovative stormwater BMPs

8. The scale of implementation of innovative water management solutions in new stormwater investments

9. The failure frequency of the available stormwater BMPs and the required frequency of their maintenance 
10. Experience in the exploitation of stormwater BMPs

11. The degree of overload of existing stormwater systems

12. The ability to control the outflow from stormwater BMPs

\section{Legal factors $(\mathrm{L})$ :}

1. The scope of requirements regarding the area development plans

2. Consistency and stability of regulations pertaining to stormwater management

3. Purposefulness and speed of implementation of binding procedures pertaining to stormwater management

4. The scope of requirements regarding the environmental impact of stormwater infrastructure

5. Regulations pertaining to collaboration between local governments, industrial facilities and research institutions

6. Preferences regarding the use of sustainable technologies within the competitive tendering system

\section{Environmental factors (E):}

1. The scale of the environmental impact of stormwater infrastructure

2. Activity of ecological organizations

3. The condition of stormwater, the receiving body of water, and the area to be drained

4. The level of groundwaters

5. Potential to improve biodiversity and green areas in cities

6. The level of reduction of the discharge of stormwater into the receiving body of water

7. Legal protection of the environment and natural resources

8. The level of implementation of innovative proecological technologies

\section{Selection and assessment of factors}

In order to eliminate elements with a negligible impact on the stormwater systems, the expert team carried out an initial preselection of all factors. Factors with the highest importance for the sustainability of the systems being studied were identified within each of the groups (Fig. 2). The identified factors were then taken into account in surveys held among the members of the expert team. Each expert assessed each case in terms of its uncertainty and impact on the subject using a 1 to 7 scale. "1" corresponded to a very low mark while "7" corresponded to a very high mark.

Figure 3 presents the averaged assessment of factors as obtained in the survey study. The orange line indicates the global average for all elements, while the blue line indicates the average values within individual factor groups. As shown in the study, economic factors were found to play a key role in the sustainability of stormwater systems as assessed by the expert team. The potential impact of these factors was estimated at 5.20 (Fig. 3a). Environmental factors (5.07) and political factors (5.02) were also above the average value (4.97). The lowest importance was ascribed to social factors (4.78). However, it must me noted that the total score for social factors is only $8 \%$ lower than that for economic factors showing that all categories have a significant impact on the analysed problem. Larger differences were observed in relation to the uncertainty of the analysed elements (Fig. 3b). The highest notes were ascribed to legal (4.20), political (4.13), and social factors (4.07). Technological factors were judged most certain as evidenced by the uncertainty score of 3.11 , with global average of 3.71 .

Figure 4 presents the results of surveys regarding the potential impact of individual factors on the sustainability of stormwater systems. Black horizontal lines illustrate the ranges of responses obtained for individual factors while blue and red dots indicate 
arithmetic means. Red dots are used for factors with the highest scores within particular categories. Vertical orange line presents the global average for all elements included in the study. The bar chart presents the share of the highest scores (6 and 7) in all responses.

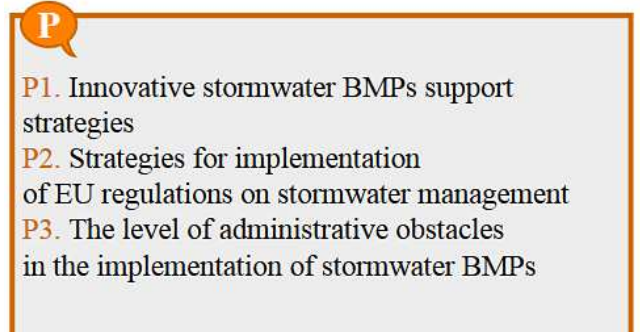

P1. Innovative stormwater BMPs support strategies

2. Strategies for implementation

of EU regulations on stormwater management

3. The level of administrative obstacles

in the implementation of stomwater BMPs

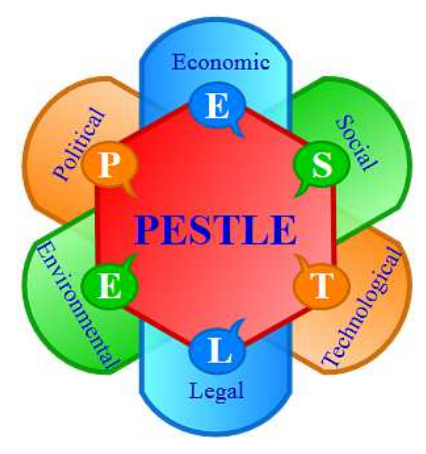

En1. The scale of the environmental impact of stormwater infrastructure

En2. The condition of stormwater, the receiving body of water, and the area to be drained En3. Legal protection of the environment and natural resources

(1)

\section{(E)}

Ec1. The costs of construction of innovative stormwater BMPs

Ec2. The scale of public support

and the availability of other funds

for the construction of stormwater BMPs

Ec3. Operating costs of stormwater BMPs

S1. Willingness to cooperate between different groups of stakeholders in the decision-making process related to the choice of a stormwater discharge system

S2. Scale of social costs of inappropriate stormwater management

S3. Residents'safety levels

T1. Availability of areas for the construction of stormwater BMPs

T2. Availability of stormwater BMPs adequate to match the size, landform, and characteristics of the area to be drained

T3. The failure frequency of the available stormwater BMPs and the required frequency of their maintenance

L1. The scope of requirements regarding the area development plans

L2. Consistency and stability of regulations pertaining to stormwater management L3. The scope of requirements regarding the environmental impact of stormwater infrastructure

Fig. 2. List of factors included in PESTLE: BMPs - Best Management Practices.

The presented results suggest little diversity of the perceived impact of individual categories. Out of all eighteen factors included in the analysis, the highest scores were ascribed to: Availability of stormwater BMPs adequate to match the size, landform, and characteristics of the area to be drained (T2), The level of administrative obstacles in the implementation of stormwater BMPs (P3) and The cost of construction of innovative stormwater BMPs (Ec1). The average scores of these factors were above 5.25, and none of the experts considered them to be insignificant. Scores above 5.00 were also ascribed to economic factors $(\mathrm{Ec} 2, \mathrm{Ec} 3)$, the environmental factor The condition of stormwater, the receiving body of water, and the area to be drained (En2) and the legal factor The scope of requirements regarding the area development plans (L1). The lowest score (4.53) was 
ascribed to the legal factor The scope of requirements regarding the environmental impact of stormwater infrastructure (L3).
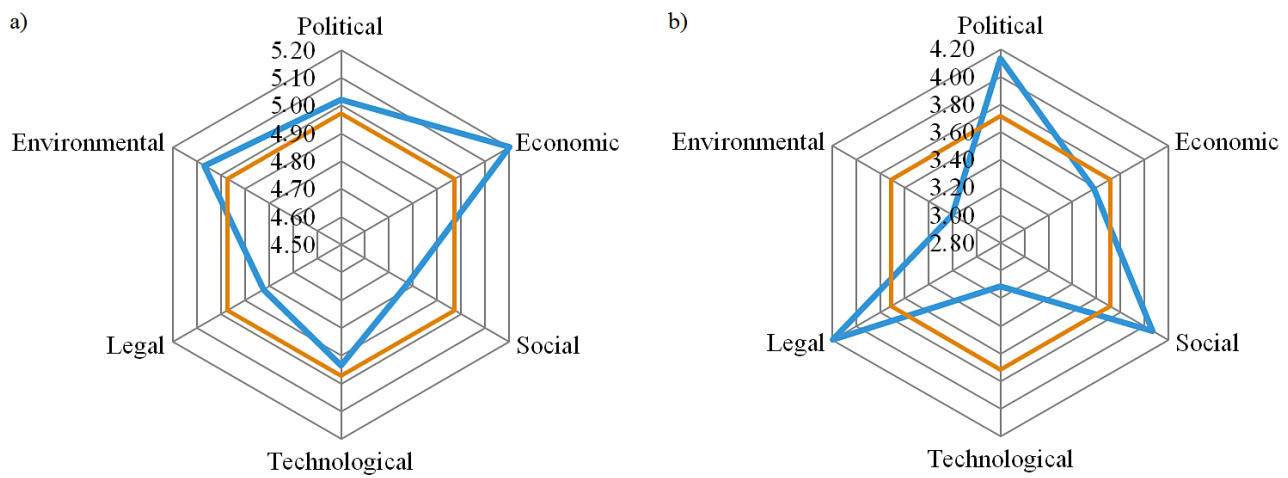

Fig. 3. The averaged assessment of factors: a) potential impact, b) uncertainty.

Figure 5, with individual markings defined as in Figure 4, presents the results of surveys pertaining to the uncertainty of individual factors within a time frame of the nearest 20 years. The presented results show a significant variation of scores both within individual groups and at the global level. The highest uncertainty score was ascribed to the social factor Willingness to cooperate between different groups of stakeholders in the decision-making process related to the choice of a stormwater discharge system (S1) and to the political factor Innovative stormwater BPMs support strategies (P1), with average scores of 5.10 and 5.00, respectively. The highest certainty was ascribed to the technological factor Availability of stormwater BMPs adequate to match the size, landform, and characteristics of the area to be drained (T2), reflecting the broad scope of available solutions for sustainable stormwater systems.

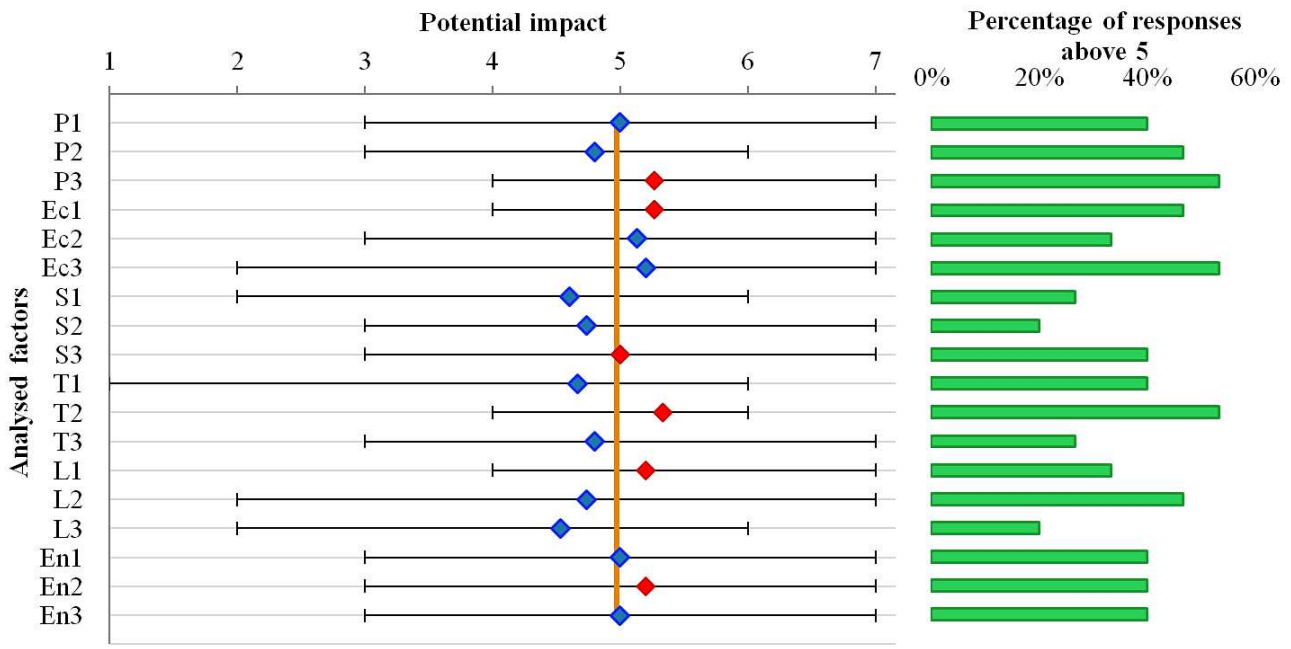

Fig. 4. The results of surveys regarding the potential impact of individual factors.

The results of the impact and uncertainty surveys were placed within the Impact/Uncertainty Grid shown in Figure 6. The factors that are marked in red, including The scope of requirements regarding the area development plans (L1), The scale of public support and the availability of other funds for the construction of stormwater BMPs (Ec2), and Innovative stormwater BPMs support strategies (P1), are critical uncertainties. The 
remaining elements located above the orange line corresponding to the average global impact of factors may be considered predetermined elements as defined in [23]. Factors located below the orange line are secondary elements [23].

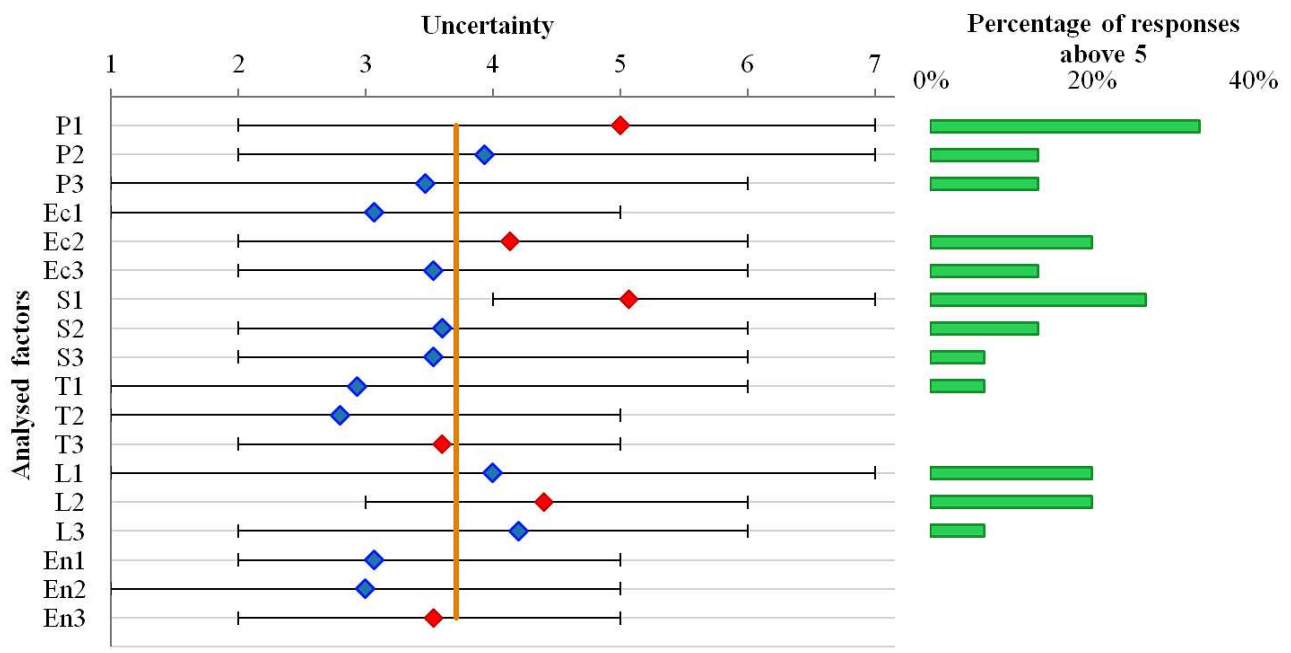

Fig. 5. The results of surveys pertaining to the uncertainty of individual factors.

\section{Conclusions}

As shown by the analysis, factors that are often marginalized or completely neglected are of key importance for the sustainability of stormwater systems. Although the importance of economic factors has been known for a long time, the importance of such elements as the promotion of innovative stormwater BMPs or area development plans taking into consideration the implementation of such solutions is usually disregarded. Therefore, focus should be placed on the education and social promotion of sustainable methods of stormwater management. Only this approach would result in increasing the degree of their implementation in urban catchment basins and thus in improving the efficacy of stormwater management in urban areas.

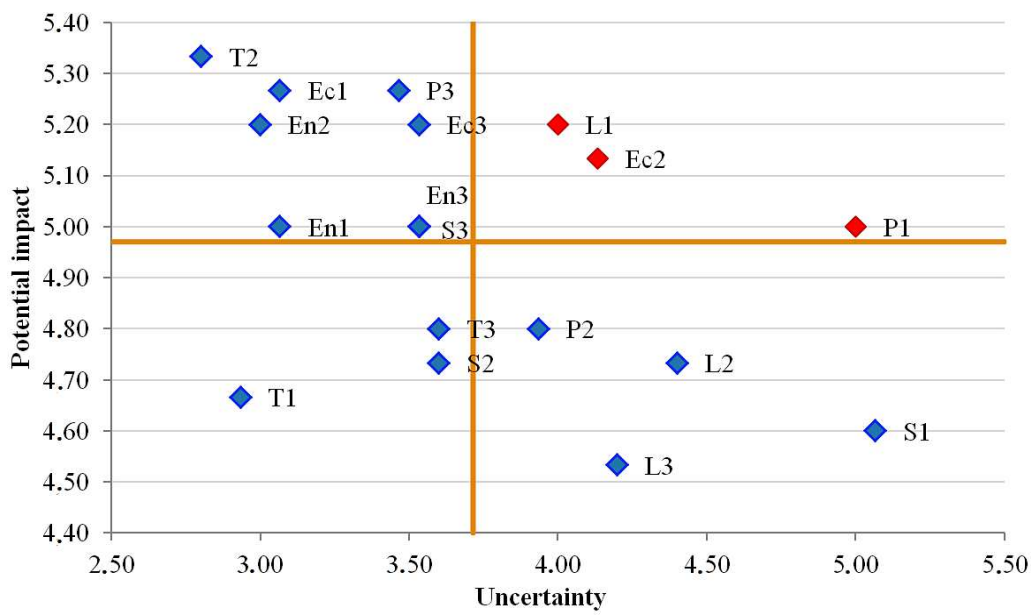

Fig. 6. The Impact/Uncertainty Grid. 


\section{References}

1. M. Maciejewski, Hydrologia w inżynierii i gospodarce wodnej vol. 1, 33-42 (2010)

2. W. Zhuang, Environ. Sci. Pollut. R. 23, 12867-12879 (2016)

3. Y.D. Gomez, L.G. Teixeira, Resour. Conserv. Recy. 127, 56-67 (2017)

4. A. Stec, A. Mazur, D. Słyś, E3S Web. Conf. 22, 00168 (2017)

5. U. Nachshon, L. Netzer, Y. Livshitz, Sustain. Cities Soc. 27, 398-406 (2016)

6. I. Skrzypczak, J. Kogut, W. Kokoszka, D. Zientek, Civ. Environ. Eng. Rep. 24, 69-82 (2017)

7. M. Zdeb, J. Zamorska, D. Papciak, J. Ecol. Eng. 17, 203-208 (2016)

8. K. Pochwat, E3S Web Conf. 17, 00075 (2017)

9. A. Stec, D. Słyś, Ecol. Chem. Eng. S 20, 381-396 (2013)

10. G. Sakson, A. Brzezińska, M. Zawilski, Ochr. Sr. 39, 27-38 (2017)

11. M. Starzec, J. Dziopak, Underground Infrastructure of Urban Areas 4, 181-191 (2018)

12. B. Tchórzewska-Cieślak, M. Włodarczyk-Makuła, J. Rak, Desalin. Water Treat. 72, 146-155 (2017)

13. M. Kida, S. Ziembowicz, P. Koszelnik, Sep. Purif. Technol. 192, 457-464 (2018)

14. P. Lynggaard, K.E. Skouby, Sensors 16, 1840 (2016)

15. A. Mazur, D. Słyś, E3S Web Conf. 17, 00058 (2017)

16. Y. Kwon, J. Hwang, Y. Seo, Sustainability 10, 1242 (2018)

17. D. Słyś, A. Stec, M. Zeleňáková, Ecol. Chem. Eng. S 19, 359-372 (2012)

18. M. Zeleňáková, G. Markovič, D. Kaposztásová, Z. Vranayová, Procedia Engineer. 89, 1515-1521 (2014)

19. Team FME, PESTLE Analysis. Strategy Skills (www.free-management-ebooks.com, 2013)

20. J. Song, Y. Sun, L. Jin, Renew. Sust. Energ. Rev. 80, 276-289 (2017)

21. D. Fozer, F.Z. Sziraky, L. Racz, T. Nagy, A.J. Tarjani, A.J. Toth, E. Haaz, T. Benko, P. Mizsey, J. Clean. Prod. 147, 75-85 (2017)

22. J. Nazarko, J. Ejdys, K. Halicka, Ł. Nazarko, A. Kanoniuk, A. Olszewska, Procedia Engineer. 182, 491-496 (2017)

23. T. Wulf, C. Brands, P. Meissner, A scenario-based approach to strategic planning. Tool description - Impact/Uncertainty Grid (HHL, Leizig, 2011)

24. C.C. Amos, A. Rahman, J.M. Gathenya, J. Clean. Prod. 172, 196-207 (2018)

25. P.F. Candine, J.S. Belém Jr, Espacios 38, 18 (2017)

26. A. Stec, S. Kordana, D. Słyś, J. Clean. Prod. 151, 193-205 (2017)

27. K. Pochwat, D. Słyś, S. Kordana, J. Hydrol. 549, 501-511 (2017)

28. D. Słyś, J. Dziopak, Pol. J. Environ. Stud. 20, 743-753 (2011)

29. M. Starzec, J. Dziopak, D. Słyś, Underground Infrastructure of Urban Areas 4, 193-200 (2018)

30. T. Zubala, Environ. Sci. Pollut. R. 25, 952-962 (2018) 